\begin{tabular}{|c|c|}
\hline Title & Flux Crystal Growth, Structure, and Optical Properties of the New Germanium Oxysulfide La 4(GeS2O2)(3) \\
\hline Author(s) & Y an, Hong; Kuwabara, A kihide; Smith, Mark D.; Y amaura, Kazunari; T sujimoto, Y oshihiro; Zur Loye, Hans Conrad \\
\hline Citation & $\begin{array}{l}\text { Crystal growth \& design, 20(6), } 4054-4061 \\
\text { https://doi.org/10.1021/acs.cgd.0c00332 }\end{array}$ \\
\hline Issue Date & 2020-06-03 \\
\hline Doc URL & http:/hdl.handle.net/2115/81629 \\
\hline Rights & $\begin{array}{l}\text { This document is the A ccepted Manuscript version of a Published W ork that appeared in final form in Crystal Growth } \\
\& \text { Design, copyright c A merican Chemical Society after peer review and technical editing by the publisher. To access } \\
\text { the final edited and published work see https:/pubs.acs.org/doi/10.1021/acs.cgd.0c00332. }\end{array}$ \\
\hline Type & article (author version) \\
\hline File Information & Flux Crystal Growth_R1_FinalV er2_Tsujimoto.pdf \\
\hline
\end{tabular}

Instructions for use 


\section{Flux Crystal Growth, Structure, and Optical Properties of the New Germanium Oxysulfide $\mathrm{La}_{4}\left(\mathrm{GeS}_{2} \mathrm{O}_{2}\right)_{3}$}

Hong Yan, ${ }^{1,2}$ Akihide Kuwabara, ${ }^{3}$ Mark D. Smith, ${ }^{4}$ Kazunari Yamaura, ${ }^{1,2}$ Yoshihiro Tsujimoto, *,1,2,4 Hans-Conrad zur Loye*,4

${ }^{1}$ Research Center for Functional Materials, National Institute for Materials Science, 1-1 Namiki, Tsukuba, Ibaraki 305-0044, Japan

${ }^{2}$ Graduate School of Chemical Sciences and Engineering, Hokkaido University, North 13 West 8, Kita-ku, Sapporo 060-0808, Japan

${ }^{3}$ Nanostructures Research Laboratory, Japan Fine Ceramics Center, 2-4-1 Mutsuno, Atsuta, Nagoya 456-8587, Japan

${ }^{4}$ Department of Chemistry and Biochemistry, University of South Carolina, Columbia, South Carolina 29208, United States

*Corresponding authors:

Yoshihiro Tsujimoto (E-mail: TSUJIMOTO.Yoshihiro@nims.go.jp)

Hans-Conrad zur Loye (E-mail: zurloye@mailbox.sc.edu) 
Keywords. flux crystal growth, oxysulfide, wide-gap insulator, germanium

\section{Abstract}

Single crystals of a new germanium oxysulfide $\mathrm{La}_{4}\left(\mathrm{GeS}_{2} \mathrm{O}_{2}\right)_{3}$ were grown out of a $\mathrm{BaCl}_{2}$ $\mathrm{CaCl}_{2}$ eutectic flux, and the crystal structure was determined via single-crystal X-ray diffraction. Ivory-white $\mathrm{La}_{4}\left(\mathrm{GeS}_{2} \mathrm{O}_{2}\right)_{3}$ crystallizes in the centrosymmetric space group $R$ 3 with lattice constants of $a=b=16.8283(3) \AA$, and $c=8.4140(2) \AA . \mathrm{Laa}_{4}\left(\mathrm{GeS}_{2} \mathrm{O}_{2}\right)_{3}$ exhibits complex three-dimensional anion order in the framework composed of unusual $\mathrm{GeS}_{2} \mathrm{O}_{2}$ tetrahedra and three types of La-centered polyhedra. Moreover, the triangular arrangement of the $\mathrm{GeS}_{2} \mathrm{O}_{2}$ tetrahedra around a columnar structure of alternating facesharing $\mathrm{LaO}_{12}$ and $\mathrm{LaS}_{6} \mathrm{O}_{6}$ units resembles that of $\mathrm{GeO}_{4}$ tetrahedra in the apatite germanate $\mathrm{La} 9.33\left(\mathrm{GeO}_{4}\right)_{6} \mathrm{O}_{2}$, which features face-sharing $\mathrm{LaO}_{9}$ columns. The combination of UV-Vis absorption measurements and first-principle calculations revealed the existence of an indirect optical band gap $\left(E_{\mathrm{g}}=3.67 \mathrm{eV}\right)$ between the valence band maximum composed of S $3 p$ orbitals and the conduction band minimum composed of La $3 d$, La $4 f, \mathrm{~S} 3 p$, and Ge $4 s$ orbitals. 


\section{Introduction}

Mixed-anion compounds, in which two or more anionic species are incorporated into one crystal structure, have provided a playground for solid-state chemists to explore unique properties. Differences in the essential characteristics of anions, i.e., ionic radius, electronegativity, oxidation state, and polarizability, often lead to short or long-range ordering of the anions, resulting in the formation of new anion sublattices and building blocks. ${ }^{1-3}$ Mixed-anion structures containing oxide ions and different period 3-5 anions, such as oxide-sulfide and oxide-arsenide combinations, exclusively exhibit long-range anion ordering, particularly anion segregation in two dimensional (2D) layers. ${ }^{4-7}$ These anion segregations can be explained by the hard-soft acid-base (HSAB) theory, ${ }^{8}$ in which highly electropositive/polarizable cations prefer to bond with highly electronegative/polarizable anions. However, exceptions to the HSAB theory, namely higher dimensional anion distributions, exist when differences in electronegativity (or polarizability) are small or when the concentration of a given anion is high compared to that of the other.

Oxychalcogenide compounds have been extensively studied because of their interesting optical properties. The incorporation of chalcogenide ions $(C h: \mathrm{S}, \mathrm{Se}, \mathrm{Te})$ into oxide sublattices raises the valence band maximum (VBM) and narrows the optical band gap, 
allowing for the tuning of the optical band gaps. ${ }^{9-10}$ These band-gap engineered properties are useful for designing visible-light active photocatalysts, as observed in many layered oxysulfides $^{9,11-13}$. The high polarizability of the chalcogenide ions also makes noncentrosymmetric oxychalcogenides promising non-linear optical materials exhibiting large second-harmonic generation (SHG) responses. Recently, our group reported a new polar zinc oxysulfide, $\mathrm{SrZn}_{2} \mathrm{~S}_{2} \mathrm{O}$, that crystallizes in the space group $P m n 2_{1}$ (no. 31) and that exhibited a large SHG response with phase matchability in contrast to non-phasematching CaZnSO, space group P63mc (no. 186). ${ }^{14-15}$ Moreover, $\mathrm{SrZn}_{2} \mathrm{~S}_{2} \mathrm{O}$ was found to be capable of reducing and oxidizing water under ultraviolet light irradiation with greater photocatalytic activity and photo-corrosion resistance than found for the mono-anionic $\mathrm{Zn}$ compounds $\mathrm{ZnO}$ and $\mathrm{ZnS}{ }^{16}$ The structure of $\mathrm{SrZn}_{2} \mathrm{~S}_{2} \mathrm{O}$ contains close-packed corrugated double layers of $\mathrm{ZnS}_{3} \mathrm{O}$ tetrahedra that are present in two distinct orientations, in which sulfide and oxide ions form a unique $2 \mathrm{D}$ arrangement in the same layer. CaZnSO possesses a similar $\mathrm{ZnS}_{3} \mathrm{O}$ building unit, however, the connectivities of these units differ: each of these two anions is isolated into separate 2D layers. Although the origins of the phase matchability and high photocatalytic activity in $\mathrm{SrZn}_{2} \mathrm{~S}_{2} \mathrm{O}$ are not yet fully understood, it appears that the new anion-order design and arrangement of the anionic building blocks plays a crucial role in generating the unusual optical properties. 
The flux crystal growth method has been recognized as a useful technique for synthesizing new mixed-anion compounds, most of which do not readily occur in singlecrystal form. ${ }^{17-20}$ In particular, alkali or alkaline earth halides, which can be easily removed with water, are widely used as fluxes for the synthesis of a wide range of new oxychalcogenides, including non-linear optical materials ${ }^{14,}{ }^{21}$, low-dimensional magnets ${ }^{22-23}$, and superconductors ${ }^{24}$. Following the discovery of $\mathrm{SrZn}_{2} \mathrm{~S}_{2} \mathrm{O}$, we applied this approach to develop new optical oxysulfide materials based on $d^{10}$ metal-centered tetrahedra. Herein, we report the flux crystal growth of the new germanium-containing oxysulfide $\mathrm{La}_{4}\left(\mathrm{GeS}_{2} \mathrm{O}_{2}\right)_{3}$ from a $\mathrm{BaCl}_{2}-\mathrm{CaCl}_{2}$ eutectic mixture. Its crystal structure, characterized by unusual $\mathrm{GeS}_{2} \mathrm{O}_{2}$ tetrahedra, 3D anion ordering, electronic structure, and optical properties, are discussed.

\section{Experimental}

Synthesis. Single crystals of $\mathrm{La}_{4}\left(\mathrm{GeS}_{2} \mathrm{O}_{2}\right)_{3}$ were grown out of a eutectic $\mathrm{BaCl}_{2}-\mathrm{CaCl}_{2}$ flux. First, $0.5 \mathrm{mmol}$ of $\mathrm{La}_{2} \mathrm{~S}_{3}$ (Alfa Aesar 99\%), $1.0 \mathrm{mmol}$ of $\mathrm{GeO}_{2}$ (Rare Metallic 99.99\%), $3.13 \mathrm{mmol}$ of $\mathrm{BaCl}_{2}$ (Rare Metallic 99.9\%), and $3.13 \mathrm{mmol}$ of $\mathrm{CaCl}_{2}$ (Rare Metallic 99.99\%) were loaded into a magnesia crucible in an Ar-filled glovebox. The crucible was sealed inside a silica tube that was evacuated to $10^{-4} \mathrm{~Pa}$. The tube containing 
the starting materials was heated in a muffle furnace to $800^{\circ} \mathrm{C}$ at $150{ }^{\circ} \mathrm{C} / \mathrm{h}$, held for $24 \mathrm{~h}$, cooled to $500{ }^{\circ} \mathrm{C}$ at $5^{\circ} \mathrm{C} / \mathrm{h}$, and then cooled to room temperature by turning the heater off. The product was washed in sonicated water and extracted from the flux. Ivory-white block $\mathrm{La}_{4}\left(\mathrm{GeS}_{2} \mathrm{O}_{2}\right)_{3}$ crystals, along with colorless transparent platelet $\mathrm{LaOCl}$ crystals, were collected via vacuum filtration. The typical dimensions of the $\mathrm{La}_{4}\left(\mathrm{GeS}_{2} \mathrm{O}_{2}\right)_{3}$ single crystals were $0.3 \times 0.3 \times 0.3 \mathrm{~mm}^{3}$ (Figure 1 ). Elemental analysis by energy-dispersive $\mathrm{X}$ ray spectroscopy (EDS) indicated a La:Ge:S atomic ratio of approximately 4.0:2.9:5.4, which is consistent with the chemical composition of the germanium oxysulfide phase. The crystal structure of $\mathrm{La}_{4}\left(\mathrm{GeS}_{2} \mathrm{O}_{2}\right)_{3}$ was determined via single-crystal X-ray diffraction.

Single crystal structure determination. X-ray intensity data from an ivory-white block crystal were collected at 301(2) K using a Bruker D8 QUEST diffractometer equipped with a PHOTON-100 CMOS area detector and an Incoatec microfocus (Mo Ka radiation, $\lambda=0.71073 \AA$ ). The data collection covered $100 \%$ of the reciprocal space to $2 \theta_{\max }=72.6^{\circ}$, with an average reflection redundancy of 14.7 and $R$ int $=0.057$ after absorption correction. The raw area-detector data frames were reduced and corrected for absorption effects using the SAINT+ and SADABS programs. ${ }^{25}{ }^{26}$ Final unit cell parameters were determined by least-squares refinement of 9908 reflections taken from the data set. An initial structural model was obtained using SHELXT. ${ }^{27}$ Subsequent difference Fourier calculations and 
full-matrix least-squares refinement against $F^{2}$ were performed with SHELXL-2018 using the ShelXle interface. ${ }^{28}$

Synchrotron X-ray Powder diffraction. Single crystals of $\mathrm{La}_{4}\left(\mathrm{GeS}_{2} \mathrm{O}_{2}\right)_{3}$ were crushed with an agate mortar and pestle to obtain fine powders for collecting synchrotron X-ray powder diffraction (SXRD) patterns and UV-Vis diffuse reflectance spectra. SXRD measurements were performed at room temperature using a one-dimensional detector installed on the NIMS BL15XU beamline at SPring-8 in Japan. The synchrotron radiation X-rays were monochromatized to a wavelength of $0.65298 \AA$. The powdered sample of $\mathrm{La} 4\left(\mathrm{GeS}_{2} \mathrm{O}_{2}\right)_{3}$ was loaded into a glass capillary tube (internal diameter: $0.2 \mathrm{~mm}$ ). The diffraction data were collected in $0.003^{\circ}$ increments over the $2-60^{\circ}$ range and analyzed by Rietveld refinement using the RIETAN-FP program. ${ }^{29}$

TGA, UV-Vis diffuse reflectance spectra, and SEM-EDS. Thermogravimetric analysis (TGA) was carried out using a PerkinElmer Pyris 1 TAG system under O2 gas flow (60 $\mathrm{mL} / \mathrm{min})$. The sample was loaded in an alumina crucible and heated to $1000{ }^{\circ} \mathrm{C}$ at $10{ }^{\circ} \mathrm{C} / \mathrm{min}$. The thermal treatment sample was analyzed by PXRD using a Rigaku MiniFlex X-ray diffractometer $(\mathrm{Cu} \mathrm{K} \alpha$ radiation). Diffuse reflectance spectroscopy measurements were performed at room temperature using a Shimazu UV-2600 spectrophotometer equipped with an ISR-2600Plus integration sphere. The diffuse 
reflectance data were internally converted to absorbance by the instrument using the Kubelka-Munk function. Single crystals of $\mathrm{La}_{4}\left(\mathrm{GeS}_{2} \mathrm{O}_{2}\right)_{3}$ were analyzed by energy dispersive X-ray spectroscopy (EDS) equipped with a scanning electron microscopy (TESCAN Vega-e SBU). All crystals were mounted on carbon tape, and the analysis was carried using an accelerating voltage of $20 \mathrm{kV}$.

Electronic structure calculations. First-principles total energy calculations of $\mathrm{La} 4\left(\mathrm{GeS}_{2} \mathrm{O}_{2}\right)_{3}$ were performed using the projector augmented wave (PAW) method $^{30-31}$ as implemented in the Vienna Ab-initio Simulation Package (VASP). ${ }^{32-34}$ The configurations of the valence electrons in the PAW potentials are $5 s^{2} 5 p^{6} 6 s^{2} 5 d^{1}$ for La, $3 d^{10} 4 s^{2} 4 p^{2}$ for Ge, $2 s^{2} 2 p^{4}$ for $\mathrm{O}$, and $3 s^{2} 3 p^{4}$ for $\mathrm{S}$, respectively. The HSEsol-type hybrid functional was adopted. ${ }^{35}$ The conventional hexagonal unit cell of $\mathrm{La} 4\left(\mathrm{GeS}_{2} \mathrm{O}_{2}\right) 3$, which was experimentally determined in this work as mentioned later, was used as an initial structure model for the first-principles total energy calculations. The cut-off energy for the plane wave basis set and the mesh size for $k$-point sampling in the Brillouin zone were set to be $550 \mathrm{eV}$ and $1 \times 1 \times 3$, respectively. Lattice constants and internal atomic positions were fully optimized until all residual forces became $<0.02 \mathrm{eV} / \AA ̊$.

\section{Results and discussion}


The single-crystal structure analysis revealed that $\mathrm{La}_{4}\left(\mathrm{GeS}_{2} \mathrm{O}_{2}\right)_{3}$ crystallizes in the space group $R-3$ (no. 148) with lattice constants of $a=b=16.8283(3) \AA$ and $c=8.4140(2)$ Å. No significant deviation from full occupancy was detected for any atom. Thus, their occupancies were fixed at unity at the final stage of the structure refinements. The details of the structural refinement are listed in Table 1. The crystallographic parameters, including the atomic coordinates and atomic displacement parameters, are summarized in Table 2; anisotropic displacement parameters are listed in Table 3.

Figure 2 shows the SXRD patterns collected from a powder sample obtained by finely grinding hand-picked single crystals of $\mathrm{La}_{4}\left(\mathrm{GeS}_{2} \mathrm{O}_{2}\right)_{3}$. The structural model determined by the single-crystal structure analysis was used for the Rietveld refinement. The calculated pattern well reproduced the observed patterns as the refinement readily converged with good reliability indices, $R_{\mathrm{wp}}=4.90 \%, R_{\mathrm{B}}=6.88 \%$, and $R_{\mathrm{F}}=3.78 \%$. Table S1 summarizes the final refined crystallographic data.

As shown in Figure 3, $\mathrm{La}_{4}\left(\mathrm{GeS}_{2} \mathrm{O}_{2}\right)_{3}$ crystallizes in a unique three-dimensional crystal structure consisting of La- and Ge-centered polyhedra. Three crystallographically nonequivalent $\mathrm{La} 1, \mathrm{La} 2$, and $\mathrm{La} 3$ atoms occupy $18 f, 3 b$, and $3 a$ Wyckoff positions, respectively; in contrast, there is only one single germanium site occupying the $18 f$ position. Two anions, namely $\mathrm{O}^{2-}$ and $\mathrm{S}^{2-}$, are fully ordered in the structure. Figure 4 
shows the local coordination environments around the La and Ge atoms. Of these three lanthanum sites, La1 and La2 are surrounded by two different anions. La1 is coordinated by three oxygen atoms at an average distance of $d \mathrm{La}-\mathrm{O} 1, \mathrm{La}-\mathrm{O} 2 \sim 2.45 \AA$ and six sulfur atoms at average distances of $d \mathrm{La}-\mathrm{S} 1 \sim 3.28 \AA$ and $d \mathrm{La}-\mathrm{S} 2 \sim 2.99 \AA$, forming a distorted gyroelongated square pyramid. Although these bond distances vary within -7 to $12 \%$ of the reference values derived from Shannon's ionic radii ${ }^{36}$, the bond-valence-sum (BVS) calculation $^{37}$ for La1 yielded 2.91, which is consistent with the nominal oxidation state of the lanthanum ions. La2 is icosahedrally coordinated by six oxygen atoms at $d \mathrm{La}-\mathrm{O} 1=$ 2.6123(19) $\AA$ and six sulfur atoms at $d \mathrm{La}-\mathrm{S} 2=3.4262(6) \AA$. The $\mathrm{La}-\mathrm{O} 1$ and $\mathrm{La}-\mathrm{S} 2$ bond distances are 5\% shorter and 7\% longer, respectively, than the sum of the ionic radii of $\mathrm{La}^{3+}$ and $\mathrm{O}^{2-} / \mathrm{S}^{2-}$. In contrast to these two lanthanum atoms, La3 is 12 -fold coordinated with only oxygen atoms, forming a relatively symmetric icosahedron $(d \mathrm{La}-\mathrm{O} 1=2.7159(19)$ $\AA, d \mathrm{La}-\mathrm{O} 2=2.7524(16) \AA)$. The bond distances between lanthanum and oxygen atoms agree well, as they are within $1 \%$ of the sum of their ionic radii. The BVS values calculated for La2 and La3 were 2.54 and 2.63, respectively, much lower than the expected values. Typically, a BVS value lower than the ideal valence is often interpreted as indicating the existence of underbonding (or tensile stress) between the metal center and the surrounding ligands. However, the reason for the low BVS values for La2 and 
La3 remains unclear. The germanium atom was tetrahedrally coordinated by two oxygen atoms at $d_{\mathrm{Ge}-\mathrm{O} 1}=1.7721(15) \AA$ and $d_{\mathrm{Ge}-\mathrm{O} 2}=1.7908(18) \AA$ and two sulfur atoms at $d_{\mathrm{Ge}-\mathrm{S} 1}$ $=2.1600(10) \AA$ and $d \mathrm{Ge-S2}=2.1707(7) \AA$. These bond distances are consistent with those calculated from the sum of $\mathrm{Ge}^{4+}$ and $\mathrm{La}^{3+}$ ionic radii with $\mathrm{O}^{2-}$ and $\mathrm{S}^{2-}$ ionic radii, and the BVS calculation for Ge gave a reasonable value of 4.15. The $\mathrm{S}-\mathrm{Ge}-\mathrm{S}$ bond angle of $124.56(3)^{\circ}$ is much larger than the $\mathrm{O}-\mathrm{Ge}-\mathrm{O}$ bond angle of $99.89(8)^{\circ}$. This can be rationalized by considering the electrostatic repulsion between the sulfide ions with the larger ionic radii.

Germanium ions coordinated tetrahedrally by two sulfide and two oxide ions are rare compared to $\mathrm{GeS}_{3} \mathrm{O}$ tetrahedra, which is often stabilized in oxysulfides having the melilite structures. ${ }^{38-39}$ To the best of our knowledge, only two other germanium-based compounds with a similar coordination geometry around the Ge center have been synthesized: $\mathrm{Na}_{2} \mathrm{GeS}_{2}(\mathrm{OH})_{2} \cdot{ }_{5} \mathrm{H}_{2} \mathrm{O}^{40}$ and $A \mathrm{GeS}_{2} \mathrm{O}(A=\mathrm{Sr}, \mathrm{Ba})^{21}$. The Ge-S and Ge-O distances and the S-Ge-S and O-Ge-O bond angles of these compounds are similar to those in $\mathrm{La}_{4}\left(\mathrm{GeS}_{2} \mathrm{O}_{2}\right)_{3}$ (Table S2), but the $\mathrm{GeS}_{2} \mathrm{O}_{2}$ tetrahedron in $\mathrm{Na}_{2} \mathrm{GeS}_{2}(\mathrm{OH})_{2} \cdot{ }_{5} \mathrm{H}_{2} \mathrm{O}$ is slightly elongated with smaller $\mathrm{S}-\mathrm{Ge}-\mathrm{S}$ and $\mathrm{O}-\mathrm{Ge}-\mathrm{O}$ bond angles.

Figure 5a shows the linkage between the La- and Ge-centered polyhedra. $\mathrm{La}_{2} \mathrm{~S}_{6} \mathrm{O}_{6}$ and $\mathrm{La}_{12} \mathrm{O}_{12}$ polyhedra share a common $\mathrm{O}_{3}$ face to form one-dimensional (1D) chains along 
the $c$ direction. Each La-based $1 \mathrm{D}$ chain is surrounded by $\mathrm{La}_{1} \mathrm{~S}_{6} \mathrm{O}_{3}$ and $\mathrm{GeS}_{2} \mathrm{O}_{2}$ polyhedra in a complex manner. The $\mathrm{La}_{2} \mathrm{~S}_{6} \mathrm{O}_{6}$ icosahedron are connected to six $\mathrm{La}_{1} \mathrm{~S}_{6} \mathrm{O}_{3}$ polyhedra and six $\mathrm{GeS}_{2} \mathrm{O}_{2}$ tetrahedra by edge-sharing through pairs of oxygen and sulfur atoms. These La1-based polyhedra are separated by Ge and La2 atoms. In contrast, the $\mathrm{La} \mathrm{O}_{12}$ icosahedron shares $\mathrm{O}_{3}$ faces with six $\mathrm{La}_{1} \mathrm{~S}_{6} \mathrm{O}_{3}$ polyhedra and $\mathrm{O}_{2}$ edges with six $\mathrm{GeS}_{2} \mathrm{O}_{2}$ tetrahedra, both of which have two different independent $z$ coordinates. Moreover, these

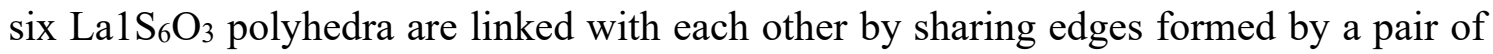
oxygen and sulfur atoms. All $\mathrm{GeS}_{2} \mathrm{O}_{2}$ tetrahedra share edges with $\mathrm{La}_{1} \mathrm{~S}_{6} \mathrm{O}_{3}, \mathrm{La}_{2} \mathrm{~S}_{6} \mathrm{O}_{6}$, and La3 $\mathrm{O}_{12}$ polyhedra.

It is interesting to compare the present oxysulfide with the germanium oxyapatite $\mathrm{La} 9.33\left(\mathrm{GeO}_{4}\right)_{6} \mathrm{O}_{2}$ that forms in the hexagonal space group $P 63 / \mathrm{m}^{41-42}$ Despite the longrange anion-ordered structure and the completely different chemical composition of $\mathrm{La}_{4}\left(\mathrm{GeS}_{2} \mathrm{O}_{2}\right)_{3}$, the oxysulfide phase of this compound exhibits Ge- and La-centered polyhedra arrangements similar to those found in the oxyapatite structure. As shown in Figure $5 b$, the $\mathrm{La} 2 \mathrm{O}_{9}$ polyhedra in the structure of $\mathrm{La} 9.33\left(\mathrm{GeO}_{4}\right)_{6} \mathrm{O}_{2}$ form an infinite 1D chain along the $c$ direction by sharing their common $\mathrm{O}_{3}$ faces as in $\mathrm{La} 4\left(\mathrm{GeS}_{2} \mathrm{O}_{2}\right)_{3}$. Moreover, these 1D chains are surrounded by $\operatorname{six} \mathrm{GeO}_{4}$ tetrahedra and six $\mathrm{La}_{7}$ polyhedra with two different $z$ coordinates, which are linked with $\mathrm{La}_{2} \mathrm{O}_{9}$ through shared 
oxygen edges and vertexes, respectively. In both $\mathrm{La}_{4}\left(\mathrm{GeS}_{2} \mathrm{O}_{2}\right)_{3}$ and $\mathrm{La} 9.33\left(\mathrm{GeO}_{4}\right)_{6} \mathrm{O}_{2}$, the $\mathrm{La} 2 / \mathrm{La} 3$ atoms are in the geometric center of the regular triangles formed by the Ge or Lal atoms. However, the Ge- or Lal-based triangles form a regular hexagon in the oxysulfide, as seen in the top-down view of these crystal structures shown in Figure 6; this is in contrast with the distorted hexagon in the oxyapatite structure.

Figure 7 shows the thermogravimetric data collected under flowing oxygen. $\mathrm{La} 4\left(\mathrm{GeS}_{2} \mathrm{O}_{2}\right)_{3}$ was stable up to $800{ }^{\circ} \mathrm{C}$, but further heating to $1000{ }^{\circ} \mathrm{C}$ resulted in a rapid weight loss by approximately $3 \%$, suggesting decomposition of the oxysulfide phase. The weight after cooling down to ambient temperature was $-2.9 \%$. As shown in Figure S1, the powder XRD measurement for the thermally treated sample revealed the formation of a germanium oxyapatite as a main phase. However, secondary phases showing relatively low intensities could not be identified.

Figure 8 shows the UV-Vis absorption spectrum of a powdered $\mathrm{La}_{4}\left(\mathrm{GeS}_{2} \mathrm{O}_{2}\right)_{3}$ sample. The absorption data were obtained by converting the sample's reflectance spectrum using the Kubelka-Munk transformation. ${ }^{43}$ The absorption curve presents two steep increases near $2.5 \mathrm{eV}$ and $3.5 \mathrm{eV}$, and the corresponding absorption edge energies, which were estimated by extrapolating the linear portions of the absorption curve to the $x$ axis, were $E_{\mathrm{g} 1}=2.23 \mathrm{eV}$ and $E_{\mathrm{g} 2}=3.67 \mathrm{eV}$, respectively. Given that the sample is ivory-white, the 
absorption at $E_{\mathrm{g} 1}$ is probably due to defects from anion vacancies, although the $\mathrm{XRD}$ analysis could detect neither anion nor cation vacancies. The larger absorption edge at $E_{\mathrm{g} 2}$ should correspond to the intrinsic optical band gap, which will be discussed below.First-principles calculations were performed to gain a better understanding of the relationship between the electronic structure and optical properties of $\mathrm{La}_{4}\left(\mathrm{GeS}_{2} \mathrm{O}_{2}\right)_{3}$. Optimized lattice constants are $a=b=16.724 \AA$ and $c=8.291 \AA$. The internal atomic coordinates of the optimized $\mathrm{La}_{4}\left(\mathrm{GeS}_{2} \mathrm{O}_{2}\right)_{3}$ unit cell are listed in Table S3. Compared with the experimental values, the present first-principles calculations somewhat underestimated the lattice constants $a$ - and $c$-axes of $\mathrm{La}_{4}\left(\mathrm{GeS}_{2} \mathrm{O}_{2}\right)_{3}$ by about $0.6 \%$ and $1.4 \%$, respectively. Internal atomic positions of the relaxed unit cell are in good agreement with the refined crystallographic data shown in Table 2. These results show that our structure optimization calculations have enough accuracy. Figures 9 and 10 show the total and partial density of states (DOS) and the electronic band dispersion curves of the oxysulfide compound. A primitive cell model converted from the computationally optimized hexagonal unit cell of $\mathrm{La}_{4}\left(\mathrm{GeS}_{2} \mathrm{O}_{2}\right)_{3}$ was used for these electronic structure calculations. The total DOS reveals an energy gap with $E_{\mathrm{g}}=4.01 \mathrm{eV}$, which is close to the $E_{\mathrm{g} 2}$ value but significantly larger than the $E_{\mathrm{g} 1}$ value. This result strongly suggests that the absorption edge observed at $E_{\mathrm{g} 2}$ is intrinsic to the electronic structure of the oxysulfide 
phase. The valence bands located between -6 and $0 \mathrm{eV}$ are mainly derived from the $\mathrm{O} 2 p$ and S $3 p$ orbitals, which are weakly hybridized with the La $3 p, 3 d$, and $4 f$ orbitals. The $\mathrm{S}$ $3 p$ bands dominate the upper energy region in the valence band maximum (VBM) compared with the $\mathrm{O} 2 p$ bands in the lower energy region, as is often observed in oxysulfide compounds. ${ }^{6,9-10}$ The conduction band minimum (CBM) is mainly composed of La $3 d$ and $4 f$, Ge $4 s$, and S $3 p$ orbitals. The electronic band dispersion curves shown in Figure 10 indicates that the VBM is located at point $\Gamma$ and the CBM between points $\mathrm{T}$ and $\mathrm{P}$. The optical absorption above $E_{\mathrm{g} 2}$ in the $\mathrm{UV}$-Vis spectrum results from the transition from the VBM to the CVM. The Ge $4 s$ and $4 p$ bands are located in the narrow energy regions between -8 and $-7 \mathrm{eV}$ and -6 and $-4 \mathrm{eV}$, respectively, and are highly hybridized with $\mathrm{O} 2 \mathrm{p}$ and $\mathrm{S} 3 \mathrm{p}$ orbitals. The localized nature of these Ge bands is in contrast to the widely dispersive La bands located in the valence bands, resulting from the isolated linkages between $\mathrm{GeS}_{2} \mathrm{O}_{2}$ tetrahedra.

\section{Conclusion}

A new germanium oxysulfide $\mathrm{La}_{4}\left(\mathrm{GeS}_{2} \mathrm{O}_{2}\right)_{3}$ with an indirect optical band gap of 3.67 $\mathrm{eV}$ was synthesized from a $\mathrm{BaCl}_{2}-\mathrm{CaCl}_{2}$ eutectic molten salt. Single-crystal structure analysis demonstrated a unique structure comprised of unusual $\mathrm{GeS}_{2} \mathrm{O}_{2}$ tetrahedra linked 
with La-centered polyhedra through corner or edge sharing. The linkage between the Geand La-centered polyhedra is similar to that observed in the germanium oxyapatite, $\mathrm{La} 9.33\left(\mathrm{GeO}_{4}\right)_{6} \mathrm{O}_{2}$, although the oxysulfide phase does not possess the so-called "apatite channel" in which oxide ions at $(00 z)$ are mobile at high temperatures. Recently, several new classes of sulfide materials have shown promise for practical use as solid-state electrolytes for Li-ion batteries. In the structures of such materials, highly polarizable sulfur ions play an important role in promoting high Li-ion conductivity. In $\mathrm{La}_{4}\left(\mathrm{GeS}_{2} \mathrm{O}_{2}\right) 3$, each $\mathrm{La}_{1} \mathrm{~S}_{6} \mathrm{O}_{3}$ polyhedron is connected to sulfide ions by edge-sharing, resulting in the formation of the sulfide-rich regions outside the alternating chains of face-sharing $\mathrm{LaO}_{12}$ and $\mathrm{LaS}_{6} \mathrm{O}_{6}$ units. Future studies should seek to determine if this three-dimensional anion order in $\mathrm{La}_{4}\left(\mathrm{GeS}_{2} \mathrm{O}_{2}\right)_{3}$ creates $\mathrm{Li}$-ion pathways via the substitution of $\mathrm{Li}$ for $\mathrm{La}$ atoms, as found in the $\mathrm{La}_{1-x} \mathrm{Li}_{y} \mathrm{TiO}_{3}$ perovskite ${ }^{44}$.

\section{ASSOCIATED CONTENT}

\section{Supporting Information.}

The following files are available free of charge.

Rietveld refinement details, Selected bond distances and bond angles, Atomic coordinates obtained by theoretical calculations, Powder X-ray diffraction pattern after 
TGA (PDF)

Crystallographic information (CIF)

\section{AUTHOR INFORMATION}

\section{Corresponding Author}

*Yoshihiro Tsujimoto. Email: TSUJIMOTO.Yoshihiro@nims.go.jp.

*Hans-Conrad zur Loye. E-mail: zurloye@mailbox.sc.edu.

\section{Notes}

The authors declare no competing financial interest.

\section{ACKNOWLEDGMENT}

We gratefully acknowledge a research grant from UofSC (NSF grant DMR-1806279). YT and AK acknowledge Grant-in-Aid for Scientific Research from Japan Society of for the Promotion Science (JSPS) (no. 16H06438, 16H06439, 16H06440, 17H05493, 19H04711). HY, KY, and YT acknowledge a research grant for Innovative Science and Technology Initiative for Security, from ATLA, Japan (no. JPJ004596). 


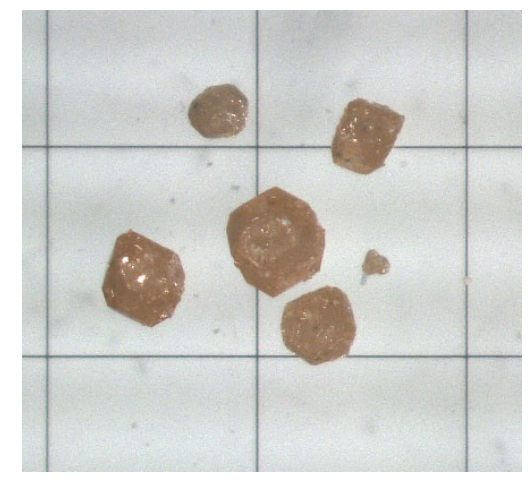

Figure 1. Photograph of single crystals of $\mathrm{La}_{4}\left(\mathrm{GeS}_{2} \mathrm{O}_{2}\right)_{3}$ on a $1 \mathrm{~mm}$ grid-cell plate.

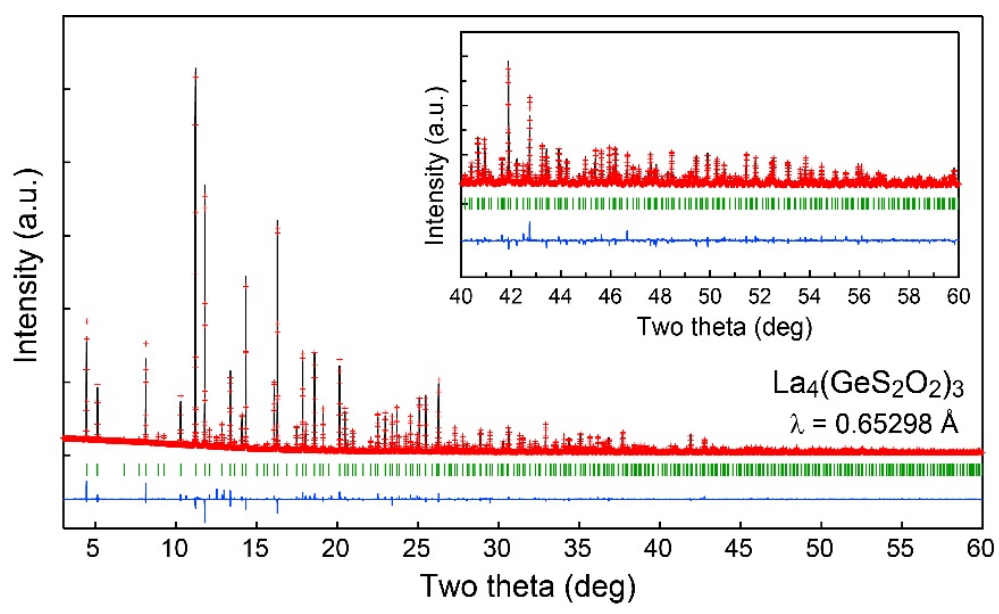

Figure 2. Synchrotron X-ray powder diffraction patterns of $\mathrm{La}_{4}\left(\mathrm{GeS}_{2} \mathrm{O}_{2}\right)_{3}$ measured at room temperature. Obtained, calculated, and difference data are presented by cross marks (red), upper solid lines (black), bottom solid lines (blue), respectively. The vertical lines (green) represented the expected Bragg peak positions of $\mathrm{La}_{4}\left(\mathrm{GeS}_{2} \mathrm{O}_{2}\right)_{3}$. 


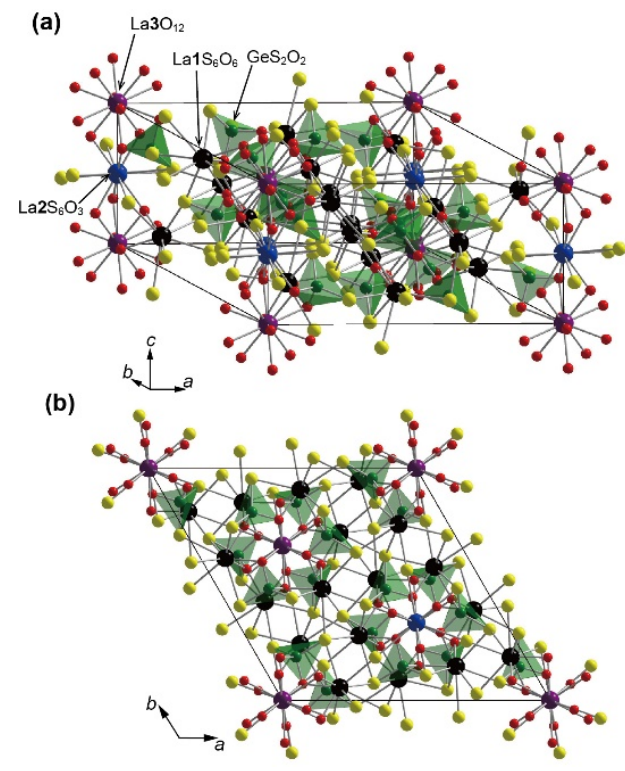

Figure 3. Crystal structure of $\mathrm{La}_{4}\left(\mathrm{GeS}_{2} \mathrm{O}_{2}\right)_{3}$. Black, blue, purple, green, red, and yellow spheres stand for La1, La2, La3, Ge, O, and S atoms, respectively.

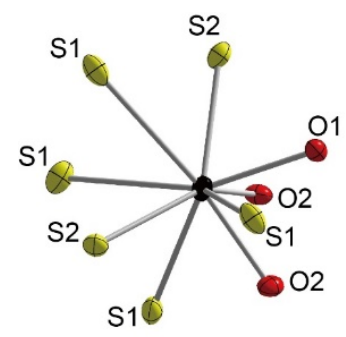

La1: $B$ VS $=2.91$

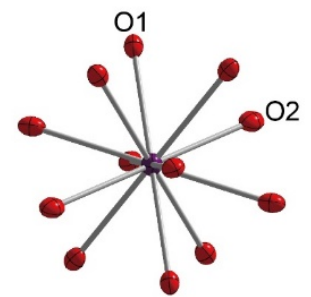

La3: $B V S=2.63$

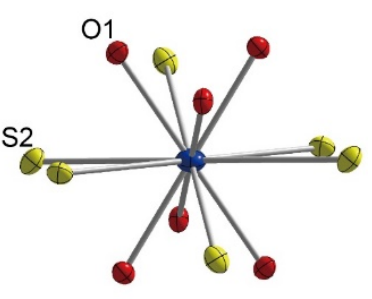

La2: BVS $=2.54$

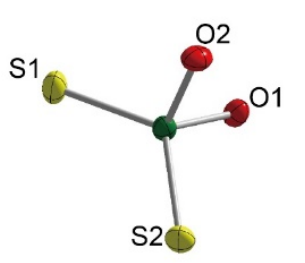

Ge: $B V S=4.15$

Figure 4. Local coordination environment around La1, La2, La3 and Ge atoms.

Displacement ellipsoids are shown at the $90 \%$ level. 

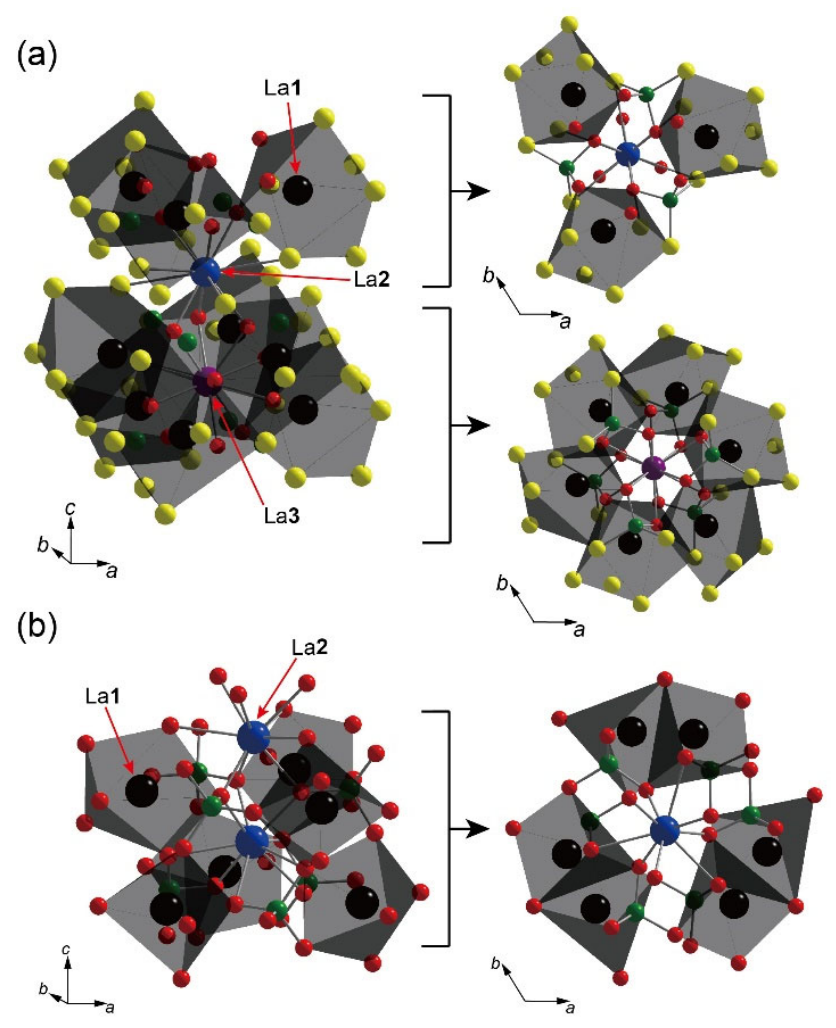

Figure 5. Linkage between La- and Ge-centered polyhedra in (a) $\mathrm{La}_{4}\left(\mathrm{GeS}_{2} \mathrm{O}_{2}\right)_{3}$ and (b) La9.33 $\left(\mathrm{GeO}_{4}\right)_{6} \mathrm{O}_{2}$ viewed along two different directions. In the former, La2- and La3centered polyhedra are surrounded by six La1-centered polyhedra and six Ge-centered tetrahedra in a different arrangement. In the latter, La2-centered polyhedra are surrounded by six La1-centered polyhedra and six Ge-centered tetrahedra in a different arrangement. 
(a)

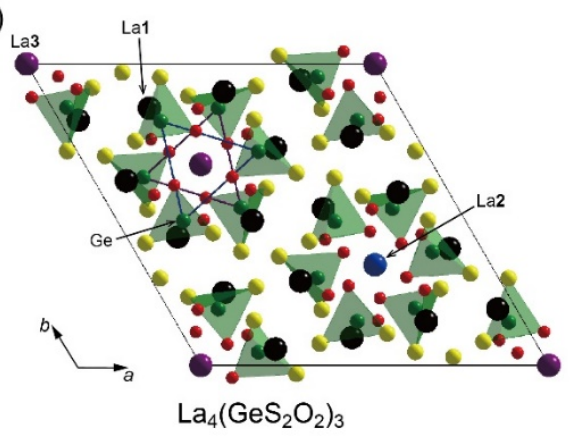

(b)

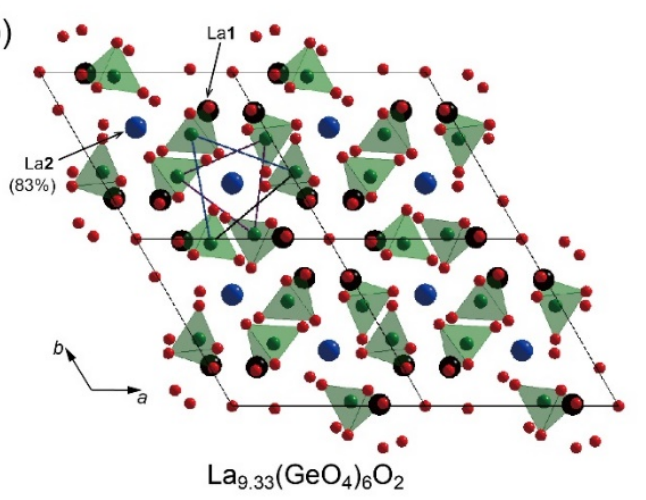

Figure 6. The crystal structure of $\mathrm{La}_{4}\left(\mathrm{GeS}_{2} \mathrm{O}_{2}\right)_{3}$ (a) and $\mathrm{La} 9.33\left(\mathrm{GeO}_{4}\right)_{6} \mathrm{O}_{2}$ (b) viewed along the $c$ axis.

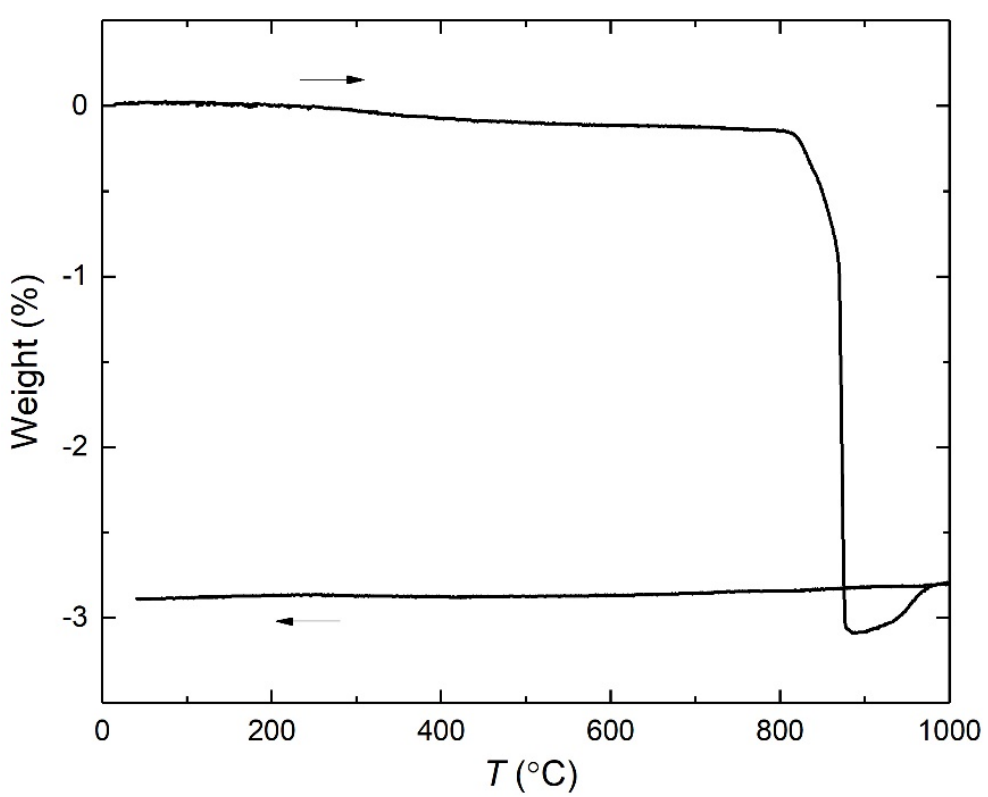

Figure 7. Thermogravimetric curve of $\mathrm{La}_{4}\left(\mathrm{GeS}_{2} \mathrm{O}_{2}\right)_{3}$, in $\mathrm{O}_{2}$ gas atmosphere. 


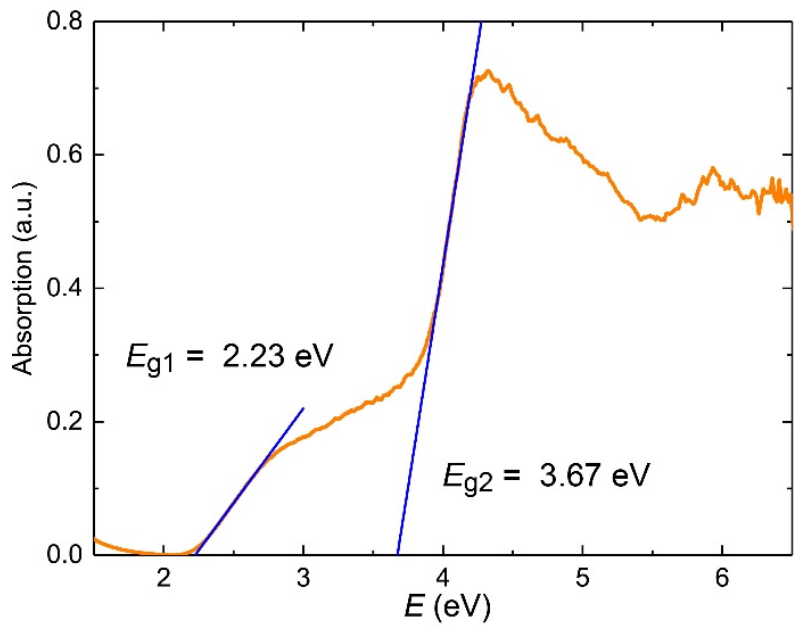

Figure 8. UV-vis optical absorption spectrum of $\mathrm{La}_{4}\left(\mathrm{GeS}_{2} \mathrm{O}_{2}\right)_{3}$, which was converted from the diffuse reflectance data using the Kubelka- Munk function. 


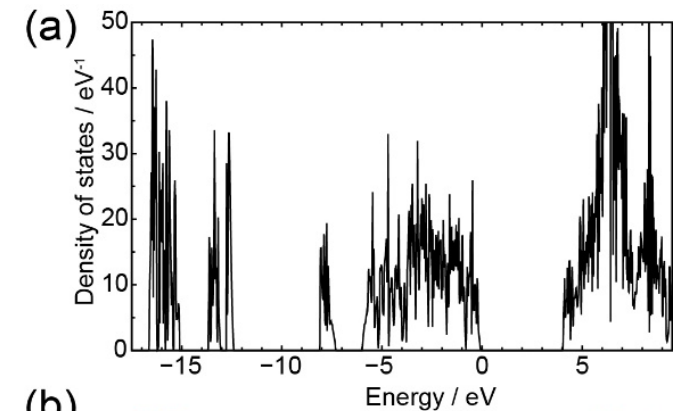

(b)

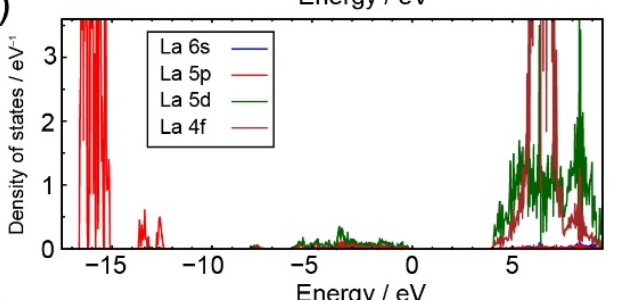

(c)

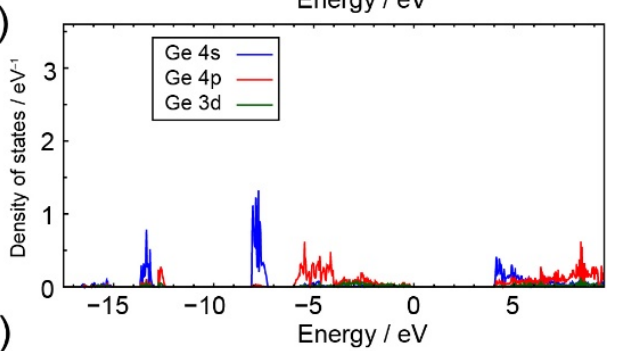

(d)

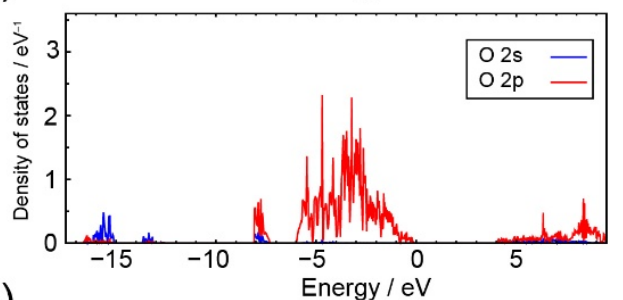

(e)

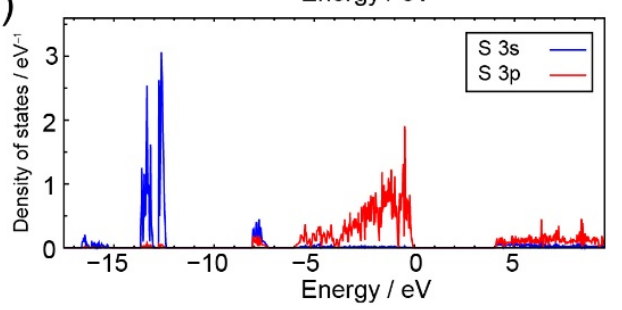

Figure 9. (a) Total and (b-e) partial density of states of $\mathrm{La}_{4}\left(\mathrm{GeS}_{2} \mathrm{O}_{2}\right)_{3}$ obtained by firstprinciples calculations based on the HSEsol hybrid functional. In the horizontal axis, the energy level of the valence band maximum is set to be $0 \mathrm{eV}$. 


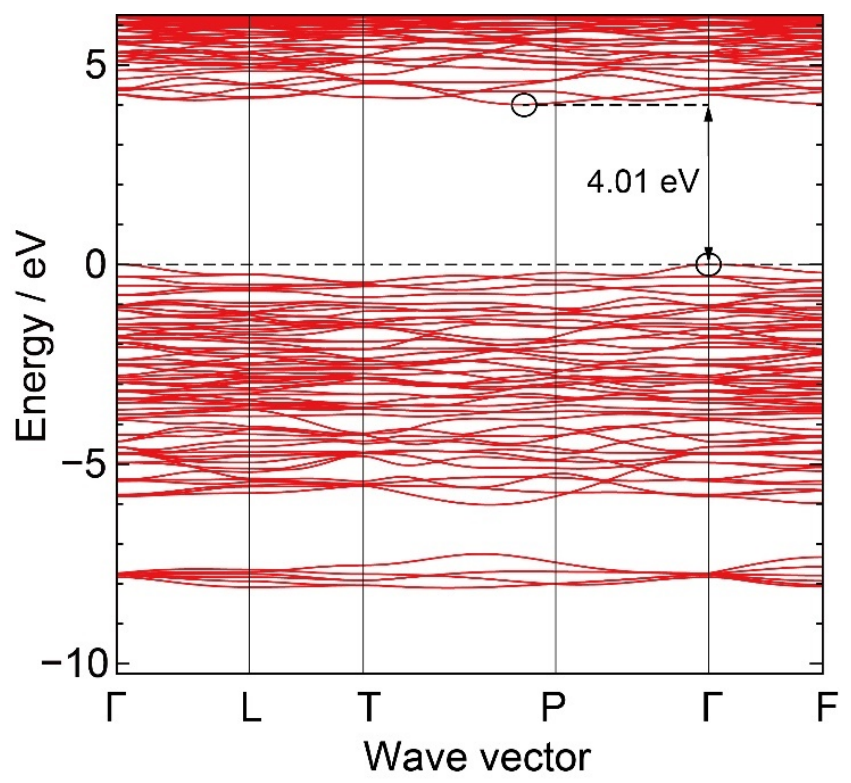

Figure 10. Electronic band dispersion curves of a primitive cell of $\mathrm{La}_{4}\left(\mathrm{GeS}_{2} \mathrm{O}_{2}\right)_{3}$ obtained by first-principles calculations based on the HSEsol hybrid functional. In the vertical axis, the highest occupied band energy level is set to be $0 \mathrm{eV}$.

Table 1. Results of the Structure Refinement of $\mathrm{La}_{4}\left(\mathrm{GeS}_{2} \mathrm{O}_{2}\right)_{3}$ Using Single-Crystal XRay Diffraction

\begin{tabular}{ll}
\hline Formula & $\mathrm{La}_{4}\left(\mathrm{GeS}_{2} \mathrm{O}_{2}\right)_{3}$ \\
Formula weight & 1061.77 \\
Radiation & $\mathrm{Mo} \mathrm{K \alpha}(\lambda=0.71073 \AA)$ \\
$T(\mathrm{~K})$ & $301(2)$ \\
Crystal system & trigonal \\
Space group & $R-3$ \\
\hline
\end{tabular}




\begin{tabular}{ll}
\hline$a(\AA)$ & $16.8283(3)$ \\
$b(\AA)$ & $16.8283(3)$ \\
$c(\AA)$ & $8.4140(2)$ \\
$V\left(\AA^{3}\right)$ & $2063.54(9)$ \\
$Z$ & 6 \\
$D_{\text {calc }}\left(\mathrm{g} / \mathrm{cm}^{3}\right)$ & 5.126 \\
$F_{000}$ & 2808 \\
no. of measured reflns & 32798 \\
no. of unique reflns & 2225 \\
no. of observed reflns & 1868 \\
$\left(F^{2}>2 \sigma\left(F^{2}\right)\right)$ & \\
$R_{\text {int }}(\%)$ & \\
$R\left[F^{2}>2 \sigma\left(F^{2}\right)\right] / w R\left(F^{2}\right)$ & $2.22 / 3.45$ \\
$(\%)$ & \\
GoF & \\
\hline
\end{tabular}

Table 2. Crystallographic and Refinement Data Obtained from Single-Crystal Structure Analysis of $\mathrm{La}_{4}\left(\mathrm{GeS}_{2} \mathrm{O}_{2}\right)_{3}$.

\begin{tabular}{lllllll}
\hline atom & site & $x$ & $y$ & $z$ & Occupancy & $U_{\text {eq }}\left(\AA^{2}\right)$ \\
\hline La1 & $18 f$ & $0.18672(2)$ & $0.24104(2)$ & $0.15890(2)$ & 1 & $0.00902(3)$ \\
La2 & $3 b$ & 0 & 0 & $1 / 2$ & 1 & $0.01243(7)$ \\
\hline
\end{tabular}




\begin{tabular}{lllllll}
\hline La3 & $3 a$ & 0 & 0 & 0 & 1 & $0.00792(6)$ \\
Ge & $18 f$ & $0.18713(2)$ & $0.04347(2)$ & $0.24397(3)$ & 1 & $0.00720(5)$ \\
$\mathrm{S} 1$ & $18 f$ & $0.26044(4)$ & $-0.02833(4)$ & $0.19177(7)$ & 1 & $0.01228(11)$ \\
$\mathrm{S} 2$ & $18 f$ & $0.22741(4)$ & $0.14889(4)$ & $0.42442(7)$ & 1 & $0.01035(11)$ \\
$\mathrm{O} 1$ & $18 f$ & $0.06959(11)$ & $-0.04136(11)$ & $0.25780(19)$ & 1 & $0.0082(3)$ \\
$\mathrm{O} 2$ & $18 f$ & $0.18462(11)$ & $0.10106(11)$ & $0.06669(18)$ & 1 & $0.0099(3)$ \\
\hline
\end{tabular}

Table 3. Anisotropic Displacement Parameters $U_{i j}\left(\AA^{2}\right)$ for $\mathrm{La}_{4}\left(\mathrm{GeS}_{2} \mathrm{O}_{2}\right)_{3}$ at $301 \mathrm{~K}$.

\begin{tabular}{llllll}
\hline$U_{11}$ & $U_{22}$ & $U_{33}$ & $U_{23}$ & $U_{13}$ & $U_{12}$ \\
\hline $0.00858(6)$ & $0.00651(6)$ & $0.01144(6)$ & $-0.00042(4)$ & $-0.00159(5)$ & $0.00338(5)$ \\
$0.01475(10)$ & $0.01475(10)$ & $0.00781(14)$ & 0 & 0 & $0.00737(5)$ \\
$0.00733(9)$ & $0.00733(9)$ & $0.00910(13)$ & 0 & 0 & $0.00366(4)$ \\
$0.00696(11)$ & $0.00689(11)$ & $0.00789(10)$ & $-0.00046(8)$ & $-0.00042(8)$ & $0.00356(9)$ \\
$0.0096(3)$ & $0.0139(3)$ & $0.0158(3)$ & $-0.0047(2)$ & $-0.0019(2)$ & $0.0077(2)$ \\
$0.0099(3)$ & $0.0099(3)$ & $0.0106(2)$ & $-0.00343(19)$ & $-0.00225(19)$ & $0.0046(2)$ \\
$0.0068(7)$ & $0.0071(7)$ & $0.0096(7)$ & $-0.0008(6)$ & $0.0010(6)$ & $0.0025(6)$ \\
$0.0136(8)$ & $0.0109(8)$ & $0.0070(7)$ & $0.0010(6)$ & $0.0002(6)$ & $0.0074(7)$ \\
\hline
\end{tabular}




\section{Reference}

1. Kageyama, H.; Hayashi, K.; Maeda, K.; Attfield, J. P.; Hiroi, Z.; Rondinelli, J. M.; Poeppelmeier, K. R., Expanding frontiers in materials chemistry and physics with multiple anions. Nat. Commun. 2018, 9, 772.

2. Tsujimoto, Y.; Yamaura, K.; Takayama-Muromachi, E., Oxyfluoride Chemistry of Layered Perovskite Compounds. Appl. Sci. 2012, 2, 206-219.

3. Keen, D. A.; Goodwin, A. L., The crystallography of correlated disorder. Nature 2015, 521, 303-309.

4. Clarke, S. J.; Adamson, P.; Herkelrath, S. J.; Rutt, O. J.; Parker, D. R.; Pitcher, M. J.; Smura, C. F., Structures, physical properties, and chemistry of layered oxychalcogenides and oxypnictides. Inorg. Chem. 2008, 47, 8473-8486.

5. Valldor, M., Anion Ordering in Bichalcogenides. Inorganics 2016, 4, 23.

6. Broadley, S.; Gal, Z. A.; Cora, F.; Smura, C. F.; Clarke, S. J., Vertex-linked $\mathrm{ZnO}_{2} \mathrm{~S}_{2}$ tetrahedra in the oxysulfide BaZnOS: a new coordination environment for zinc in a condensed solid. Inorg. Chem. 2005, 44, 9092-9096.

7. Zhu, W. J.; Hor, P. H., Crystal Structure of New Layered Oxysulfides: $\mathrm{Sr}_{3} \mathrm{Cu}_{2} \mathrm{Fe}_{2} \mathrm{O}_{5} \mathrm{~S}_{2}$ and $\mathrm{Sr}_{2} \mathrm{CuMO}_{3} \mathrm{~S}$ (M=Cr, Fe, In). J. Solid State Chem. 1997, 134, 128-131.

8. Pearson, R. G., Hard and Soft Acids and Bases. J. Am. Chem. Soc. 1963, 85, 3533-3539. 9. Goto, Y.; Seo, J.; Kumamoto, K.; Hisatomi, T.; Mizuguchi, Y.; Kamihara, Y.; Katayama, M.; Minegishi, T.; Domen, K., Crystal Structure, Electronic Structure, and Photocatalytic Activity of Oxysulfides: $\mathrm{La}_{2} \mathrm{Ta}_{2} \mathrm{ZrS}_{2} \mathrm{O}_{8}, \mathrm{La}_{2} \mathrm{Ta}_{2} \mathrm{TiS}_{2} \mathrm{O}_{8}$, and $\mathrm{La}_{2} \mathrm{Nb}_{2} \mathrm{TiS}_{2} \mathrm{O}_{8}$. Inorg. Chem. 2016, 55, 36743679.

10. Yashima, M.; Ogisu, K.; Domen, K., Structure and electron density of oxysulfide $\mathrm{Sm}_{2} \mathrm{Ti}_{2} \mathrm{~S}_{2} \mathrm{O}_{4.9}$, a visible-light-responsive photocatalyst. Acta Crystallogr., Sect. B: Struct. Sci. 2008, 64, 291-298.

11. Kabbour, H.; Sayede, A.; Saitzek, S.; Lefevre, G.; Cario, L.; Trentesaux, M.; Roussel, P., Structure of the water-splitting photocatalyst oxysulfide $\alpha-\mathrm{LaOlnS}_{2}$ and ab initio prediction of new polymorphs. Chem. Commun. 2020, 56, 1645-1648.

12. Wang, Q.; Nakabayashi, M.; Hisatomi, T.; Sun, S.; Akiyama, S.; Wang, Z.; Pan, Z.; Xiao, X.; Watanabe, T.; Yamada, T.; Shibata, N.; Takata, T.; Domen, K., Oxysulfide photocatalyst for visible-light-driven overall water splitting. Nat. Mater. 2019, 18, 827-832.

13. Ogisu, K.; Ishikawa, A.; Teramura, K.; Toda, K.; Hara, M.; Domen, K., LanthanumIndium Oxysulfide as a Visible Light Driven Photocatalyst for Water Splitting. Chem. Lett. 2007, $36,854-855$. 
14. Tsujimoto, Y.; Juillerat, C. A.; Zhang, W.; Fujii, K.; Yashima, M.; Halasyamani, P. S.; zur Loye, H.-C., Function of Tetrahedral $\mathrm{ZnS}_{3} \mathrm{O}$ Building Blocks in the Formation of $\mathrm{SrZn}_{2} \mathrm{~S}_{2} \mathrm{O}: \mathrm{A}$ Phase Matchable Polar Oxysulfide with a Large Second Harmonic Generation Response. Chem. Mater. 2018, 30, 6486-6493.

15. Sambrook, T.; Smura, C. F.; Clarke, S. J.; Ok, K. M.; Halasyamani, P. S., Structure and physical properties of the polar oxysulfide CaZnOS. Inorg. Chem. 2007, 46, 2571-2574.

16. Nishioka, S.; Kanazawa, T.; Shibata, K.; Tsujimoto, Y.; Zur Loye, H. C.; Maeda, K., A zinc-based oxysulfide photocatalyst $\mathrm{SrZn}_{2} \mathrm{~S}_{2} \mathrm{O}$ capable of reducing and oxidizing water. Dalton Trans. 2019, 48, 15778-15781.

17. Fjellvag, O. S.; Nygard, K. H.; Vajeeston, P.; Sjastad, A. O., Advances in the LiCl salt flux method and the preparation of phase pure $\mathrm{La}_{2-x} \mathrm{Nd}_{x} \mathrm{LiHO}_{3}(0</=x</=2)$ oxyhydrides. Chem. Commun. 2019, 55, 3817-3820.

18. Hosono, A.; Masubuchi, Y.; Yasui, S.; Takesada, M.; Endo, T.; Higuchi, M.; Itoh, M.; Kikkawa, S., Ferroelectric $\mathrm{BaTaO}_{2} \mathrm{~N}$ Crystals Grown in a $\mathrm{BaCN}_{2}$ Flux. Inorg. Chem. 2019, 58, 16752-16760.

19. Zhong, C.; Kato, D.; Takeiri, F.; Fujii, K.; Yashima, M.; Nishiwaki, E.; Fujii, Y.; Koreeda, A.; Tassel, C.; Abe, R.; Kageyama, H., Single Crystal Growth of Sillén-Aurivillius Perovskite Oxyhalides $\mathrm{Bi}_{4} \mathrm{NbO}_{8} \mathrm{X}(\mathrm{X}=\mathrm{Cl}, \mathrm{Br})$. Inorganics 2018, 6, 41 .

20. Juillerat, C. A.; Moore, E. E.; Morrison, G.; Smith, M. D.; Besmann, T.; Zur Loye, H. C., Versatile Uranyl Germanate Framework Hosting 12 Different Alkali Halide 1D Salt Inclusions. Inorg. Chem. 2018, 57, 11606-11615.

21. Zhang, X.; Xiao, Y.; Wang, R.; Fu, P.; Zheng, C.; Huang, F., Synthesis, crystal structures and optical properties of noncentrosymmetric oxysulfides $\mathrm{AeGeS}_{2} \mathrm{O}(\mathrm{Ae}=\mathrm{Sr}, \mathrm{Ba})$. Dalton Trans. 2019, 48, 14662-14668.

22. Blandy, J. N.; Liu, S.; Smura, C. F.; Cassidy, S. J.; Woodruff, D. N.; McGrady, J. E.; Clarke, S. J., Synthesis, Structure, and Properties of the Layered Oxide Chalcogenides $\mathrm{Sr}_{2} \mathrm{CuO}_{2} \mathrm{Cu}_{2} \mathrm{~S}_{2}$ and $\mathrm{Sr}_{2} \mathrm{CuO}_{2} \mathrm{Cu}_{2} \mathrm{Se}_{2}$. Inorg. Chem. 2018, 57, 15379-15388.

23. Lei, H.; Ryu, H.; Ivanovski, V.; Warren, J. B.; Frenkel, A. I.; Cekic, B.; Yin, W.-G.; Petrovic, C., Structure and physical properties of the layered iron oxychalcogenide $\mathrm{BaFe}_{2} \mathrm{Se}_{2} \mathrm{O}$. Phys. Rev. B 2012, 86, 195133.

24. Nagao, M.; Miura, A.; Urushihara, D.; Maruyama, Y.; Goto, Y.; Mizuguchi, Y.; Moriyoshi, C.; Kuroiwa, Y.; Wang, Y.; Watauchi, S.; Asaka, T.; Takano, Y.; Tadanaga, K.; Tanaka, I., Flux Growth and Superconducting Properties of (Ce,Pr)OBiS 2 Single Crystals. Front. Chem. 2020, 8, 44. 
25. Krause, L.; Herbst-Irmer, R.; Sheldrick, G. M.; Stalke, D., Comparison of silver and molybdenum microfocus $\mathrm{X}$-ray sources for single-crystal structure determination. J. Appl.

Crystallogr. 2015, 48, 3-10.

26. Bruker AXS Inc., Madison, Wisconsin, USA, APEX3 Version 2016.5-0 and SAINT+ Version 8.37A. 2016.

27. Sheldrick, G. M., Crystal structure refinement with SHELXL. Acta Crystallogr., Sect. C: Struct. Chem. 2015, 71, 3-8.

28. Hubschle, C. B.; Sheldrick, G. M.; Dittrich, B., ShelXle: a Qt graphical user interface for SHELXL. J. Appl. Crystallogr. 2011, 44, 1281-1284.

29. Izumi, F.; Momma, K., Three-Dimensional Visualization in Powder Diffraction. Solid State Phenom. 2007, 130, 15-20.

30. Blochl, P. E., Projector augmented-wave method. Phys. Rev. B 1994, 50, 1795317979.

31. Kresse, G.; Joubert, D., From ultrasoft pseudopotentials to the projector augmentedwave method. Phys. Rev. B 1999, 59, 1758-1775.

32. Kresse, G.; Hafner, J., Ab initio molecular dynamics for liquid metals. Phys. Rev. $B$ 1993, 47, 558-561.

33. Kresse, G.; Furthmüller, J., Efficiency of ab-initio total energy calculations for metals and semiconductors using a plane-wave basis set. Comput. Mater. Sci. 1996, 6, 15-50.

34. Kresse, G.; Furthmuller, J., Efficient iterative schemes for ab initio total-energy calculations using a plane-wave basis set. Phys. Rev. B 1996, 54, 11169-11186.

35. Schimka, L.; Harl, J.; Kresse, G., Improved hybrid functional for solids: the HSEsol functional. J. Chem. Phys. 2011, 134, 024116.

36. Shannon, R. D., Revised effective ionic radii and systematic studies of interatomic distances in halides and chalcogenides. Acta Crystallogr., Sect. A: Found. Crystallogr. 1976, 32, 751-767.

37. Brese, N. E.; O'Keeffe, M., Bond-valence parameters for solids. Acta Crystallogr., Sect. B: Struct. Sci. 1991, 47, 192-197.

38. Teske, C. L., Über Oxidsulfide mit Åkermanitstruktur $\mathrm{CaLaGa}_{3} \mathrm{~S}_{6} \mathrm{O}, \mathrm{SrLaGa}_{3} \mathrm{~S}_{6} \mathrm{O}$, $\mathrm{La}_{2} \mathrm{ZnGa}_{2} \mathrm{~S}_{6} \mathrm{O}$ und $\mathrm{Sr}_{2} \mathrm{ZnGe}_{2} \mathrm{~S}_{6} \mathrm{O}$. Z. Anorg. All. Chem. 1985, 531, 52-60.

39. Endo, T.; Doi, Y.; Wakeshima, M.; Suzuki, K.; Matsuo, Y.; Tezuka, K.; Ohtsuki, T.; Shan, Y. J.; Hinatsu, Y., Magnetic Properties of the Melilite-Type Oxysulfide $\mathrm{Sr}_{2} \mathrm{MnGe}_{2} \mathrm{~S}_{6} \mathrm{O}$ : Magnetic Interactions Enhanced by Anion Substitution. Inorg. Chem. 2017, 56, 2459-2466.

40. Krebs, B.; Wallstab, H.-J., Thio-hydroxo Anions of Germanium: Preparation, Structure and Properties of $\mathrm{Na}_{2} \mathrm{GeS}_{2}(\mathrm{OH})_{2} \cdot 5 \mathrm{H}_{2} \mathrm{O}$. Z. Naturforsch., B: J. Chem. Sci. 1981, 36, 1400-1406. 
41. Berastegui, P.; Hull, S.; Garcı Garcı, F. J.; Grins, J., A Structural Investigation of $\mathrm{La}_{2}\left(\mathrm{GeO}_{4}\right) \mathrm{O}$ and Alkaline-Earth-Doped $\mathrm{La}_{9.33}\left(\mathrm{GeO}_{4}\right)_{6} \mathrm{O}_{2}$. J. Solid State Chem. 2002, 168, 294-305.

42. León-Reina, L.; Losilla, E. R.; Martínez-Lara, M.; Bruque, S.; Aranda, M. A. G., Interstitial oxygen conduction in lanthanum oxy-apatite electrolytes. J. Mater. Chem. 2004, 14, 1142-1149.

43. Kubelka, P.; Munk, F. Ein Beitrag Zur Optik Der Farbanstriche. Z. Techn. Phys. 1931, $12,593-601$.

44. Inaguma, Y., Lithium ion conductivity in the perovskite-type $\mathrm{LiTaO}_{3}-\mathrm{SrTiO}_{3}$ solid solution. Solid State lonics 1995, 79, 91-97. 


\section{For Table of Contents Use Only}

Flux Crystal Growth, Structure, and Optical Properties of the New Germanium Oxysulfide $\mathrm{La} 4\left(\mathrm{GeS}_{2} \mathrm{O}_{2}\right)_{3}$

Hong Yan, Akihide Kuwabara, Mark D. Smith, Kazunari Yamaura, Yoshihiro Tsujimoto, and Hans-Conrad zur Loye

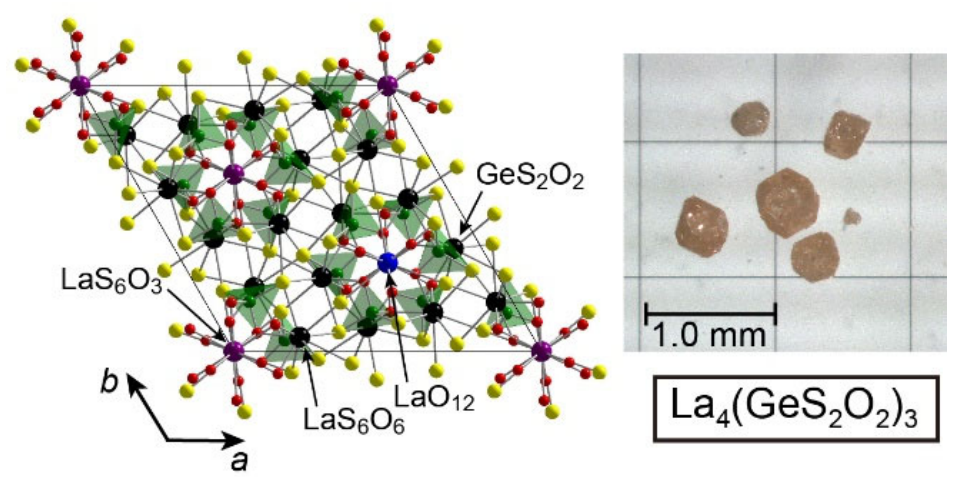

Single crystals of a new germanium oxysulfide $\mathrm{La}_{4}\left(\mathrm{GeS}_{2} \mathrm{O}_{2}\right)_{3}$ were grown out of a $\mathrm{BaCl}_{2}$ $\mathrm{CaCl}_{2}$ eutectic flux. $\mathrm{La}_{4}\left(\mathrm{GeS}_{2} \mathrm{O}_{2}\right)_{3}$ crystallizes in the centrosymmetric space group $R-3$ and shows complex three-dimensional anion order in the framework, composed of unusual $\mathrm{GeS}_{2} \mathrm{O}_{2}$ tetrahedra and three types of La-centered polyhedra. 


\section{Supporting Information}

Table S1. Atomic Coordinates and Isotropic Displacement Parameters $U_{\text {iso }}$ Refined from SXRD Data

Collected from $\mathrm{La}_{4}\left(\mathrm{GeS}_{2} \mathrm{O}_{2}\right)_{3}$ at Room Temperature.

\begin{tabular}{lllllll}
\hline Atom & Site & $x$ & $y$ & $z$ & Occp. $^{a}$ & $U_{\text {iso }}\left(\AA^{2} \times 10^{2}\right)$ \\
\hline La1 & $18 f$ & $0.18640(7)$ & $0.24115(7)$ & $0.15842(12)$ & 1 & $0.780(15)$ \\
La2 & $3 b$ & 0 & 0 & $1 / 2$ & 1 & $1.11(6)$ \\
La3 & $3 a$ & 0 & 0 & 0 & 1 & $0.43(4)$ \\
Ge & $18 f$ & $0.18670(9)$ & $0.04372(13)$ & $0.24143(17)$ & 1 & $0.45(3)$ \\
S1 & $18 f$ & $0.2602(3)$ & $-0.0272(2)$ & $0.1898(4)$ & 1 & $1.26(8)$ \\
S2 & $18 f$ & $0.2273(2)$ & $0.1531(2)$ & $0.4181(4)$ & 1 & $1.54(9)$ \\
O1 & $18 f$ & $0.0679(5)$ & $-0.0441(6)$ & $0.2503(9)$ & 1 & $0.18(14)^{b}$ \\
O2 & $18 f$ & $0.1753(5)$ & $0.0996(7)$ & $0.0684(9)$ & 1 & $0.18^{b}$ \\
\hline
\end{tabular}

The space group is $R-3$ (No. 148) with $a=b=16.82677(1) \AA, c=8.41591(1) \AA . R$ indices are $R_{\mathrm{wp}}=4.90 \%, R_{\mathrm{B}}=6.88 \%$, and $R_{\mathrm{F}}=3.78 \%$. ${ }^{a}$ Site occupancy for each atom

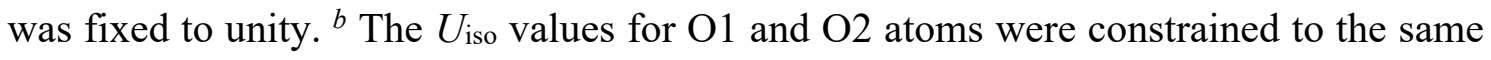
value.

Table S2. Selected Interatomic Distances $(\AA)$ and Bond Angles $\left(^{\circ}\right)$ of $\mathrm{La}_{4}\left(\mathrm{GeS}_{2} \mathrm{O}_{2}\right)_{3}$

\begin{tabular}{llll}
\hline \multicolumn{3}{c}{ bond distance $(\AA)$} & bond angle $\left(^{\circ}\right)$ \\
\hline La1-O1 & $2.473(2)$ & O2-La1-O2 & $73.36(6)$ \\
La1-O1 & $2.4228(19)$ & O2-La1-O1 & $73.67(5)$ \\
\hline
\end{tabular}




\begin{tabular}{|c|c|c|c|}
\hline & $2.464(3)$ & O2-La1-O1 & $74.01(5)$ \\
\hline \multirow[t]{4}{*}{ La1-S1 } & $3.1571(7)$ & O1-La2-O1×6 & $65.62(6)$ \\
\hline & $3.2076(7)$ & O1-La2-O1×6 & $114.38(6)$ \\
\hline & $3.3468(7)$ & O1-La2-O1×2 & 180.000 \\
\hline & $3.4280(8)$ & O1-La2-S2×4 & $61.99(4)$ \\
\hline \multirow[t]{2}{*}{ La1-S2 } & $2.9877(8)$ & O1-La2-S2×6 & 118.01(4) \\
\hline & $2.9905(7)$ & O1-La2-S2×6 & $115.82(4)$ \\
\hline $\mathrm{La} 2-\mathrm{O} 1 \times 6$ & $2.6123(19)$ & O1-La2-S2×6 & $64.18(4)$ \\
\hline $\mathrm{La} 2-\mathrm{S} 2 \times 6$ & $3.4262(6)$ & O1-La2-S2×6 & $62.06(4)$ \\
\hline La3-O1×6 & $2.7159(16)$ & O1-La2-S2×6 & $117.94(4)$ \\
\hline $\mathrm{La} 3-\mathrm{O} 2 \times 6$ & $2.7524(16)$ & S2-La2-S2×5 & $63.363(6)$ \\
\hline Ge1-O1 & $1.7720(16)$ & S2-La2-S2×5 & $116.637(6)$ \\
\hline Ge1-O2 & $1.7908(16)$ & $\mathrm{S} 2-\mathrm{La} 2-\mathrm{S} 2 \times 3$ & 180.000 \\
\hline Ge1-S1 & $2.1600(6)$ & O1-La3-O1×6 & $117.18(5)$ \\
\hline \multirow[t]{9}{*}{ Ge1-S2 } & $2.1701(6)$ & O1-La3-O1×6 & $62.82(5)$ \\
\hline & & O1-La3-O1×3 & $180.00(8)$ \\
\hline & & O1-La3-O2×6 & $120.17(5)$ \\
\hline & & $\mathrm{O} 1-\mathrm{La} 3-\mathrm{O} 2 \times 6$ & $65.81(5)$ \\
\hline & & $\mathrm{O} 1-\mathrm{La} 3-\mathrm{O} 2 \times 6$ & $114.19(5)$ \\
\hline & & O1-La3-O2×6 & $59.83(5)$ \\
\hline & & $\mathrm{O} 2-\mathrm{La} 3-\mathrm{O} 2 \times 6$ & $115.95(2)$ \\
\hline & & $\mathrm{O} 2-\mathrm{La} 3-\mathrm{O} 2 \times 6$ & $64.05(2)$ \\
\hline & & O1-Ge1-O2 & $99.89(7)$ \\
\hline
\end{tabular}




\begin{tabular}{cc}
\hline O1-Ge1-S1 & $106.40(5)$ \\
O2-Ge1-S1 & $107.94(5)$ \\
O1-Ge1-S2 & $112.29(5)$ \\
O2-Ge1-S2 & $102.86(5)$ \\
S1-Ge1-S2 & $124.56(2)$ \\
\hline
\end{tabular}

Table S3. Internal atomic coordinates of $\mathrm{La}_{4}\left(\mathrm{GeS}_{2} \mathrm{O}_{2}\right)_{3}$ obtained by structure optimization based on the HSEsol hybrid functional calculations.

\begin{tabular}{lllll}
\hline Atom & Site & $x$ & $Y$ & $z$ \\
\hline La1 & $18 f$ & 0.186 & 0.240 & 0.159 \\
La2 & $3 b$ & 0 & 0 & $1 / 2$ \\
La3 & $3 a$ & 0 & 0 & 0 \\
Ge & $18 f$ & 0.187 & 0.043 & 0.246 \\
S1 & $18 f$ & 0.260 & -0.029 & 0.190 \\
S2 & $18 f$ & 0.228 & 0.149 & 0.427 \\
O1 & $18 f$ & 0.068 & -0.042 & 0.258 \\
O2 & $18 f$ & 0.183 & 0.101 & 0.066 \\
\hline
\end{tabular}




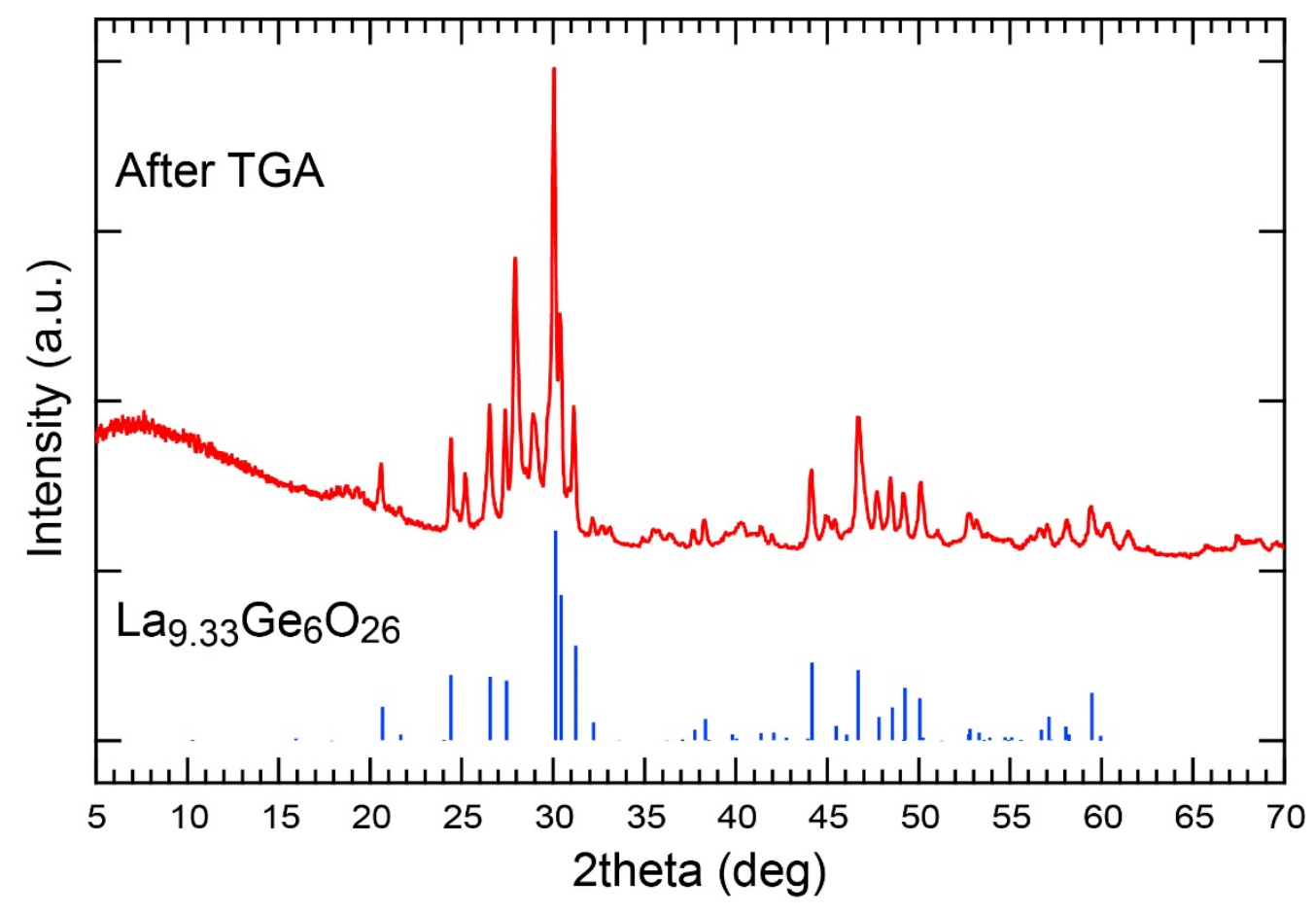

Figure S1. Room-temperature powder XRD pattern of the product after TG measurement.

Major peaks could be assigned to a germanium oxyapatite, $\mathrm{La}_{9.33} \mathrm{Ge}_{6} \mathrm{O}_{26}$ [1], but many peaks with relatively low intensities, which are probably assigned to secondary phases, could not be identified.

\section{Reference.}

1. Berastegui, P.; Hull, S.; Carcía, F. J.; Grins, J., J. Solid State Chem. 2002, 168, 294305. 